\title{
Pathways to Enhance Climate Change Resilience among Pastoral Households in Northern Tanzania
}

\author{
Ronald Boniphace Ndesanjo, Ida Theilade, and \\ Martin Reinhardt Nielsen
}

\section{Contents}

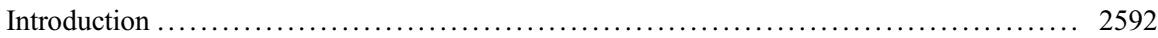

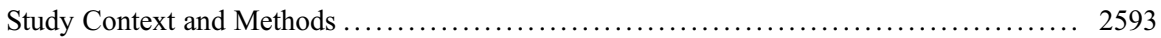

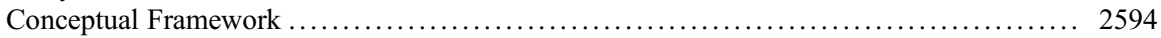

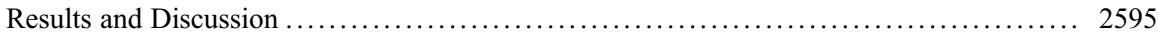

Local Climatic Trends ................................................ 2595

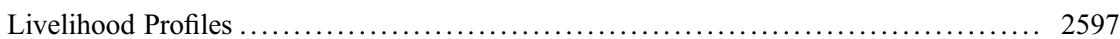

Household Vulnerability .................................................. 2597

Climate Change Adaptive Strategies .................................... 2601

Local Institutional Mechanisms and Climate Change Resilience ..................... 2603

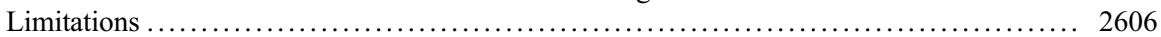

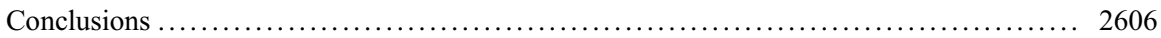

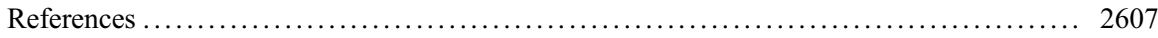

\section{Abstract}

The objective of this study was to evaluate the pathways to enhance resilience to increased climate variability and directional change among pastoral households in Simanjiro District in Northern Tanzania. The study used household survey and rainfall and temperature data. Results indicate increasing temperature

This chapter was previously published non-open access with exclusive rights reserved by the Publisher. It has been changed retrospectively to open access under a CC BY 4.0 license and the copyright holder is "The Author(s)". For further details, please see the license information at the end of the chapter.

R. B. Ndesanjo ( $\square)$

Institute of Development Studies, University of Dar es Salaam, Dar es Salaam, Tanzania e-mail: ronald.ndesanjo@gmail.com

I. Theilade $\cdot$ M. R. Nielsen

Department of Food and Resource Economics, Section for Global Development,

University of Copenhagen, Copenhagen, Denmark

e-mail: idat@ifro.ku.dk; mrni@ifro.ku.dk 
and decreasing precipitation trends over the past four decades. Also, extreme climatic events, particularly drought, have become more frequent. Food and water insecurity are key factors causing an increased household vulnerability. Increased climate change-induced malaria prevalence poses additional health risks. Household adaptive strategies include livelihood diversification and migration. Local institutions are instrumental in enhancing climate change resilience at the local level. We conclude that livelihood diversification and migration are key pathways to enhancing households' climate change resilience.

\section{Keywords}

Adaptation $\cdot$ Agro-pastoralism $\cdot$ Climate change $\cdot$ Resilience $\cdot$ Tanzania

\section{Introduction}

There is a strong consensus that temperatures, based on medium emissions scenarios, are likely to rise by more than $2{ }^{\circ} \mathrm{C}$ in most parts of Africa by the end of the century (Orlove 2019). Concomitantly, extreme events such as tropical cyclones, increasing rainfall intensity, and increased probability of drought are gradually becoming common (Kangalawe 2017; Pauline et al. 2017). Climate change impacts are already experienced in many locations (Pardoe et al. 2018). At a local level, these changes are manifested in many ways including shifts of rain seasons, erratic rains, extreme droughts and precipitation, strong winds, and higher temperatures (Berkhout 2012; Suckall et al. 2014). These changes have brought about adverse livelihood impacts such as reduced crop yields and changes in the crop calendar (Berkhout 2012; Mertz et al. 2009).

Climate change vulnerability is considered higher in developing countries due to particular socio-economic and ecological conditions that increase people's exposure to risk factors and reduce the adaptive capacities. Extreme events such as droughts and floods increase particularly rural livelihoods vulnerability because they rely more on climatic conditions (Sewando et al. 2016). Observed and projected changes in local climate conditions in Tanzania include precipitation variability increasing between $5 \%$ and $45 \%$ accompanied by a temperature rise of $2-4{ }^{\circ} \mathrm{C}$ (Trærup and Mertz 2011). The northern part of the country is reported to have undergone a shift in the onset of rainfall between 1980 and 2004 (Trærup and Mertz 2011). Associated with these changes are extreme events such as floods and a rise in human, crop, and animal diseases. Together, these changes adversely affect crop, mobility, and migration patterns among rural communities (Rodima-Taylor 2012).

The livestock sector in sub-Saharan Africa faces negative impacts of climate change (Suryabhagavan 2017). In Tanzania, livestock husbandry faces higher risks from these impacts associated with altered productivity in rangelands. Reduced productivity may adversely affect pastoral livelihoods and the economy of the entire livestock sector in the country. Apart from pastoral communities, the general population is likely to be negatively affected through high reliance on food products from grazing animals (Godber and Wall 2014). 
Pastoral vulnerability will be further exacerbated by other livelihood stresses that characterize rural livelihoods. This includes high population growth in the context of a declining and highly dynamic resource base in Simanjiro District (Woodhouse and McCabe 2018; Lynn 2010). The combination of these effects with stressors ranging from short term drought and extreme precipitation events to long-term climatic shifts is likely to reduce further pastoralists' ability to sustain their current livelihoods system. The aim of this study was, therefore, to evaluate pathways to enhance resilience to increasing climate variability as well as directional climate change among pastoral households in Simanjiro District, Northern Tanzania. The study sought to answer four main questions: (a) What are the climate patterns and trends in the study area? (b) What is the status of household vulnerability to impacts of increasing climate variability and directional climate change? (c) What are the adaptive strategies employed by pastoralists in the study area in response to increasing climate variability and directional climate change? (d) What is the role of local institutions in enhancing the resilience of pastoral households to increasing climate variability and directional climate change?

\section{Study Context and Methods}

Covering an area of $20,591 \mathrm{~km}^{2}$, Simanjiro District is located in Manyara Region of Northern Tanzania. The area's topography stretches from vast plains to scattered ridges and hill valleys. Climate is semi-arid with annual rainfall ranging between 650 and $700 \mathrm{~mm}$. Rainfall is bimodal with short rains lasting from November to December and long rains from February to May. Temperatures range between $13{ }^{\circ} \mathrm{C}$ and $30{ }^{\circ} \mathrm{C}$ characterized by cold months from May to July and hot months between August and February (Homewood et al. 2009; Pittiglio et al. 2012). Livestock husbandry is common in drier areas while agro-pastoralism is predominantly practiced in wetter areas (Baird and Leslie 2013). The Maasai is the dominant ethnic group in the district, herding livestock of mainly indigenous stock $(90 \%)$. Maize, beans, pigeon peas, wheat, and sunflower are the main crops grown for both commercial and consumption purposes (Baird and Leslie 2013).

The study used multiple data sources and data collection methods. Study wards were selected purposively based on the predominance of livestock production as the main occupation. Also, ward-specific factors such as livelihoods-ecological interlinkages were used to determine study wards. Household questionnaire surveys were conducted in eleven villages selected in four wards, namely, Endonyongijape, Emboreet, Loiborsiret, and Langai. Random sampling was used to select households targeting the household head. Key informants were selected using purposive sampling (Angelsen et al. 2012; Baird 2014). Household surveys were conducted between May and July 2014. Three aspects were used as measures of household vulnerability to climate change and respective adaptive strategies. These include food, water, and health. Food and water were assessed in terms of their availability (or lack thereof) and health situation was assessed in terms of the prevalence of climatically driven diseases. Adaptive strategies were assessed based on how 
households responded to cases of food and water scarcity as well as disease prevalence. Key informant interviews were conducted between February and March 2015. Household survey data $(n=297)$ and in-depth interviews $(n=24)$ were analyzed using descriptive statistical analysis. Monthly precipitation and temperature data were acquired from the Tanzania Meteorological Agency (TMA). Trend analysis was used to analyze climate data.

\section{Conceptual Framework}

This study adopted and operationalized the Sustainable Livelihood Framework (Chambers and Conway 1992) that has been widely used in socio-economic research on a range of topics falling within the poverty, livelihoods, and environment nexus (Reed et al. 2013). The framework offers useful analytical and empirical tools to order information and to understand the nature and interlinkages among livelihood aspects. The framework is built on four main components namely livelihood outcomes, livelihood assets, livelihood strategies, and the institutional context (Fig. 1). The institutional context is conceived as a crucial factor for sustainable livelihoods and for promoting local-level climate change resilience. For livelihood outcomes, the focus is on the household's vulnerability and

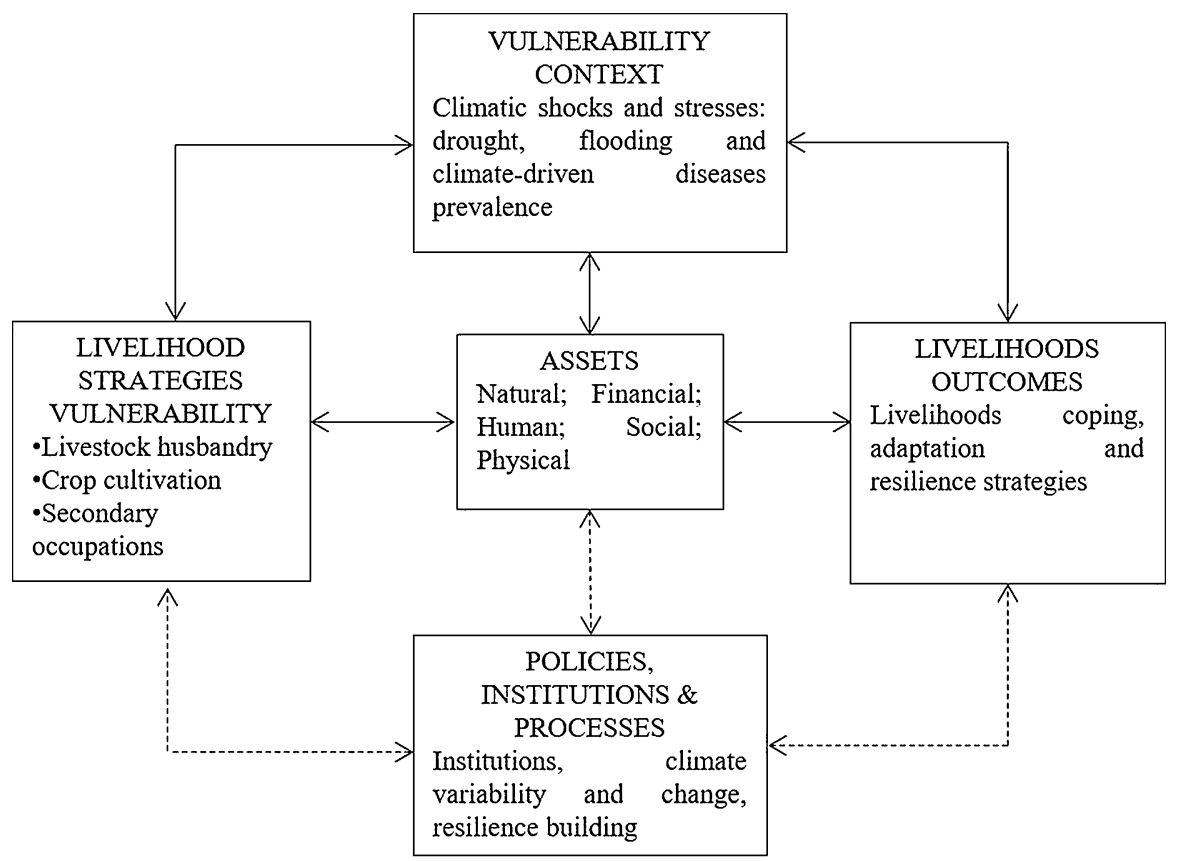

Fig. 1 Sustainable livelihoods framework. (Source: Adapted and modified from Chambers and Conway 1992) 
responsive adaptation strategies. All four aspects are embedded in a vulnerability context as it is influenced by climate stressors and shocks.

The study was structured around local socio-ecological contexts that influence key livelihood strategies among study households. The policy environment and local resource management processes formed the institutional context. The vulnerability context is addressed by looking mainly at climate shocks adversely affecting household livelihoods, including drought, flooding, and diseases. These aspects are embedded in the four research questions of the study.

\section{Results and Discussion}

\section{Local Climatic Trends}

Temperature and rainfall trends are summarized in Figs. 2, 3, and 4. Fitted temperature values indicate an increment in average minimum temperatures of about $2{ }^{\circ} \mathrm{C}$ in the period from 1972 to 2013 . Data show that the late 1970s to mid-1980s and early 1990s registered lower average minimum temperatures compared to the late 1980 s and late 2000s, with relatively higher average minimum temperatures recorded. The average maximum temperature trend portrays a similar pattern with an overall increase in average maximum temperature of about $1.5^{\circ} \mathrm{C}$ across the fourdecade period based on the fitted line. However, the noted increment in average maximum temperature is statistically insignificant with $25 \% \mathrm{R}$-squared. The mid1980 s and late 1990s saw low average annual maximum temperatures. High average temperatures were recorded in the early and late 1980 s as well as the first half of the 2000s. The R-squared value for the average minimum temperature indicates a statistically significant $(72 \%)$ increase in minimum temperature over the 40 years.

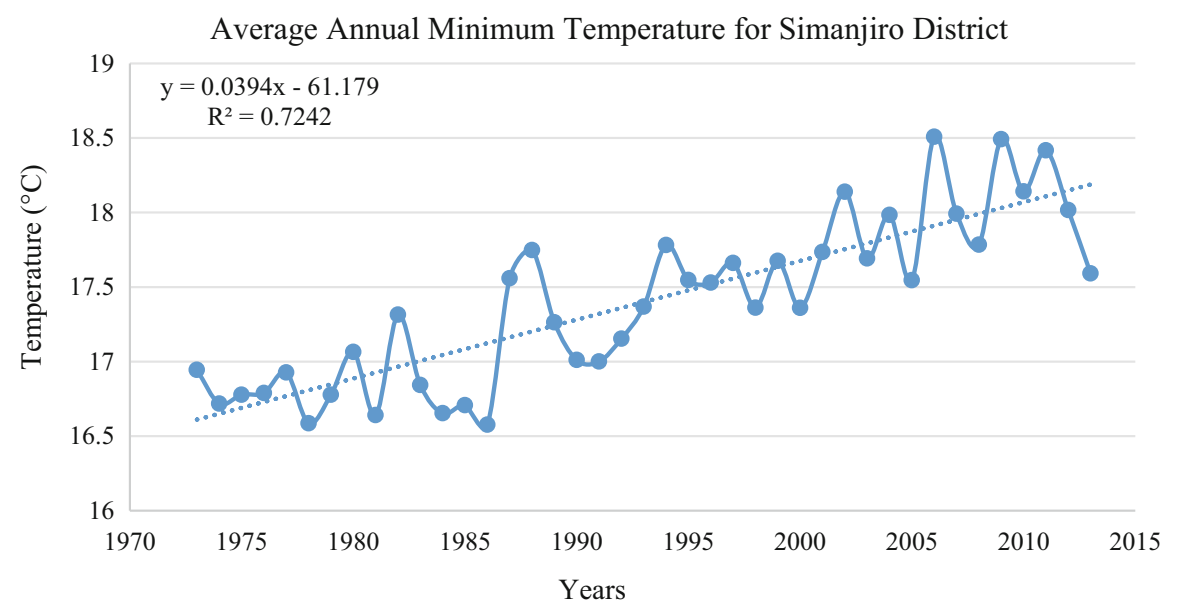

Fig. 2 Average annual minimum temperature for Simanjiro District. (Source: Ndesanjo 2017) 


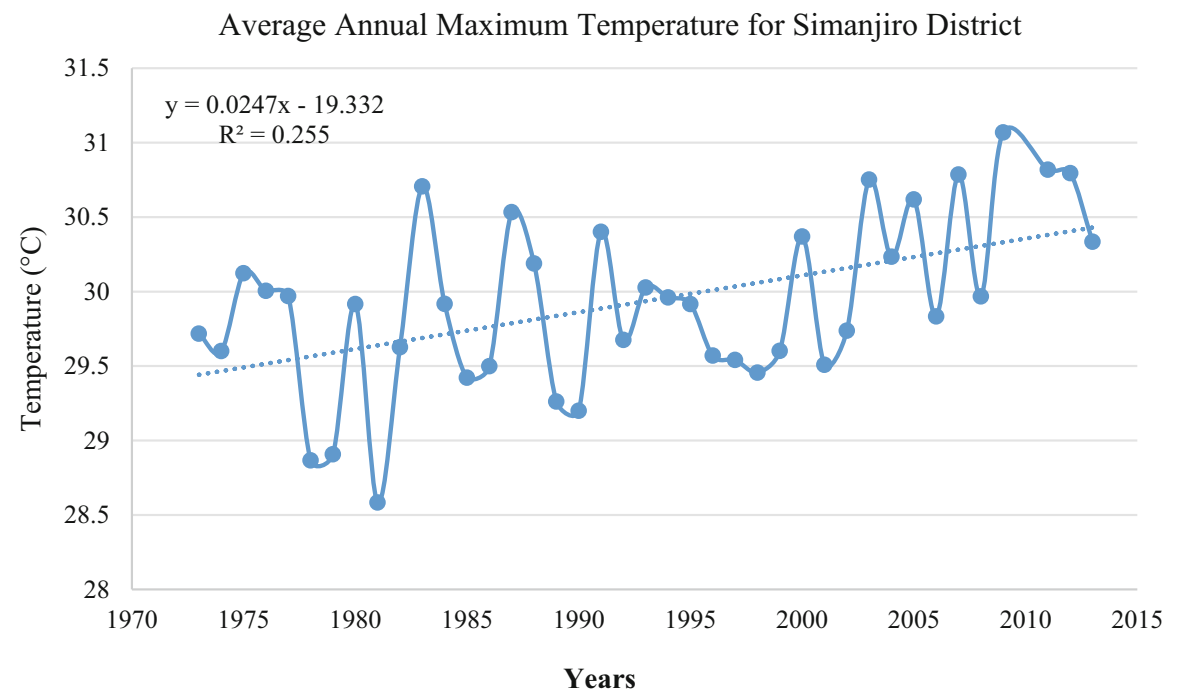

Fig. 3 Average annual maximum temperature for Simanjiro District. (Source: Ndesanjo 2017)

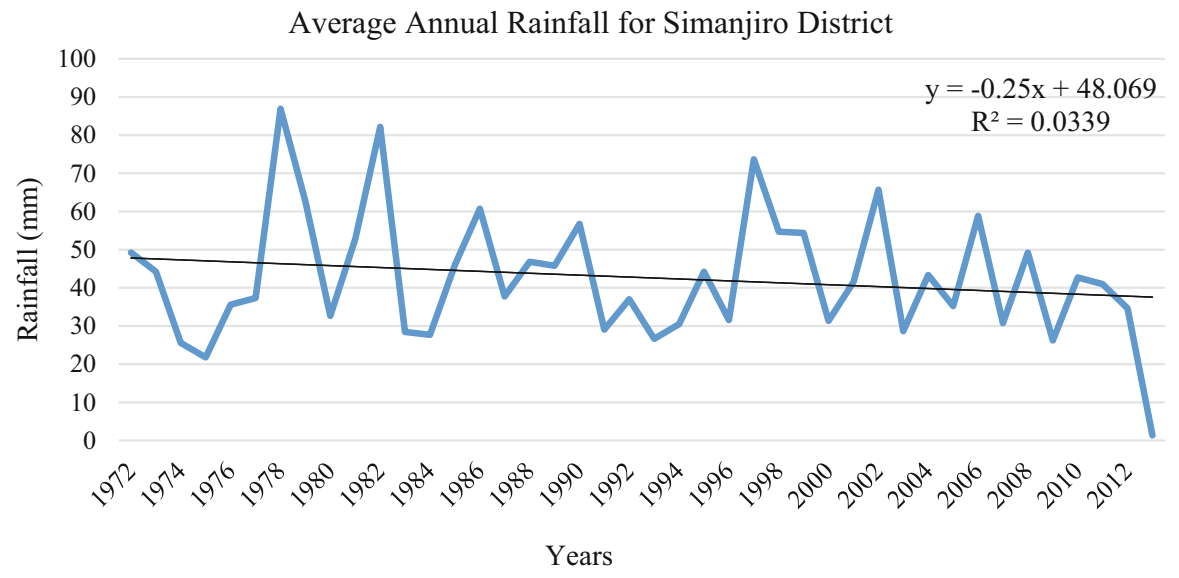

Fig. 4 Average annual rainfall for Simanjiro District. (Source: Ndesanjo 2017)

The rainfall trend indicates high average annual rainfall between the late 1970s and 1980s, late 1990, as well as early to mid-2000s compared to the mid-1970s, the first half of the 1980s and 2013 that saw a relatively low average rainfall. Overall, the 40 -year data record in the study area reveals a decreasing but statistically insignificant trend in precipitation with an R-squared value of $3 \%$.

Similar temperature and rainfall trends at both the country and continent levels have been noted in other studies such as that by Trærup and Mertz (2011) indicating temperature increase ranging between 2 and $4{ }^{\circ} \mathrm{C}$ combined with 
increasing precipitation variability on an increasing trend ranging from $5 \%$ to $45 \%$ in Tanzania. A study by (Pauline et al. 2017) indicates increasing extreme rainfall frequency. However, contrary to observations made in the two studies, the current study depicts a decreasing precipitation trend. Similar predictions were made by Paavola (2008) indicating decreasing precipitation up to $20 \%$ by 2100 . The year 2013 saw extremely low rainfall, which may overly influence the predicted rainfall trend. However, no substantial difference was noted when omitting the year 2013 from the analysis.

\section{Livelihood Profiles}

The majority of surveyed households (86\%) pursued an agro-pastoralist livelihood strategy. Other livelihood strategies were rare but include trade and wage employment by $(3 \%)$ and $(2 \%)$ of the households respectively. Off-farm labor and subsistence herding employ few households each at (2\%). About $6 \%$ of households reported being engaged in a range of other livelihood occupations.

These results imply that apart from livestock husbandry as the main occupation in the study area, there is increasing adoption of crop farming suggesting a shift to agro-pastoralism as the main livelihood strategy. The increasing common combination of livestock and crop production reflects local communities' strategies to reduce the necessity to sell cattle to acquire food as well as a strategy to safeguard property (land) rights. Other drivers of increasing cultivation in the area include immigration by farming communities, drought, and livestock diseases, as well as government policies aiming to settle the Massai (Homewood et al. 2009). The relatively low percentage engaging in trading and wage employment may be attributed to cultural factors that discourage secondary economic activities. Hence, even when household members engage in secondary income activities, they usually invest the proceeds in livestock and farming (Homewood et al. 2009).

\section{Household Vulnerability}

The percentage frequency of common food items consumed is summarized in Fig. 5. Grain, legumes, meat, and milk contribute equally and constitute about $70 \%$ of food items consumed. Vegetables, bananas, and other food items are not commonly consumed.

Grain and milk have been widely documented as common foods in Maasai households (Hodgson 2011; Homewood 2004; McCabe et al. 2010). However, legumes are not common in Maasai pastoralists' diets. Discussions with household members during fieldwork indicate that the inclusion of legumes in their diets is an influence of other ethnic groups that have migrated to Simanjiro in recent years. Particularly, the Waarusha's (another Maa speaking ethinic group originating from neighboring Arusha) diet commonly contains legumes (mostly black beans locally known as ngwara). Although reported consumed with a high 


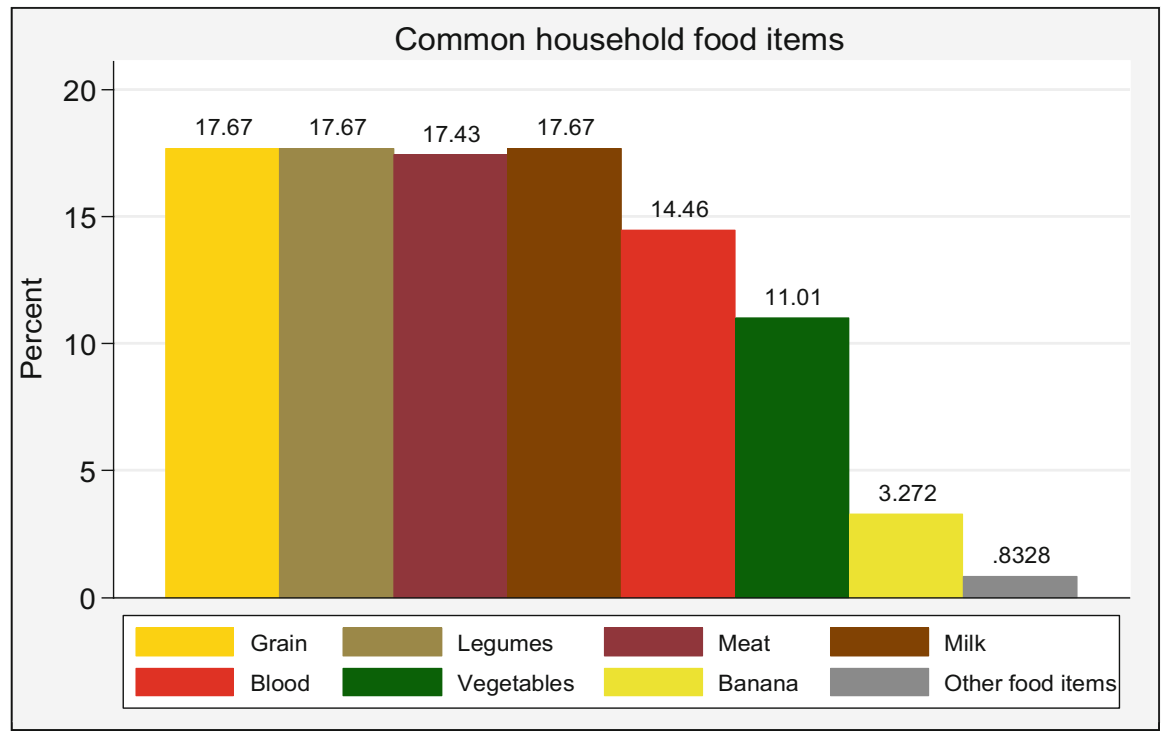

Fig. 5 Common food items consumed by households (numbers above the bars indicate percentage frequency). (Source: Ndesanjo 2017)

frequency, meat and blood are mainly consumed during special events and ceremonies, for instance, meat-eating feasts among Maasai warriors or initiation ceremonies. Besides, meat is a delicacy consumed at local weekly markets across Maasailand. Maasai rarely consume vegetables or bananas. The few records of these food items are most likely from non-Maasai households. Food consumption patterns depicted here indicate that livestock still is an important food source for most households either directly consumed or indirectly as a means to earn an income with which to meet other food requirements. However, as shown by Berkhout (2012) high dependence on livestock to supply household food requirements can increase climate change vulnerability in the long run.

Households were asked to rate food sufficiency during the previous 12 months and the results are presented in Fig. 6. There is no significant difference across the four wards in household food sufficiency ratings. About $63 \%$ reported that they had "somewhat sufficient" food while $29 \%$ reported a "somewhat insufficient" food supply during the past 12 months. Only $1 \%$ of the households reported a "very insufficient" food supply. Respondents were also asked about experienced incidents of household food insecurity and the exact months in which they occurred. The majority of households (78\%) reported experiencing food insecurity between four and six months in the previous twelve months. The months in which food insecurity occurred are described in Fig. 6. These results point to food shortage incidents concentrating in the dry season lasting from August to December. This implies that food security is seasonal deterministic and that vulnerability will likely increase as a result of climate-induced exacerbation of drought in the dry season. 


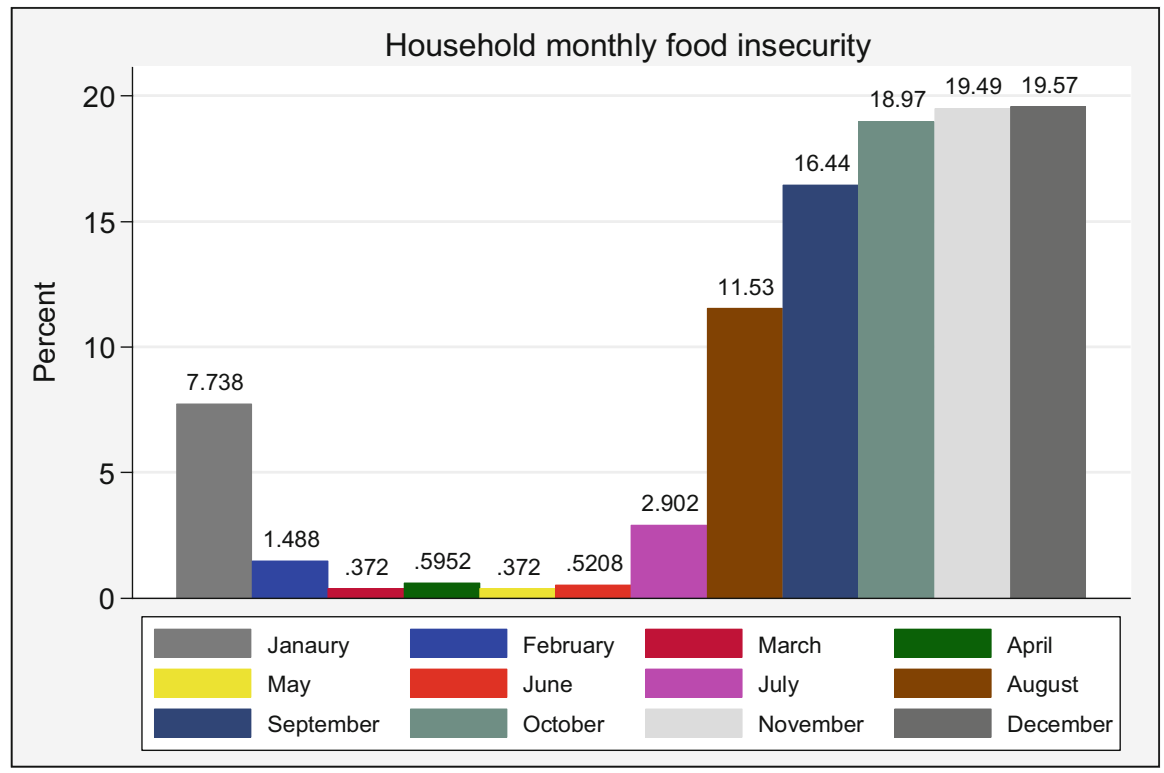

Fig. 6 Monthly household food insecurity incidents (numbers above the bars indicate percentage frequency). (Source: Ndesanjo 2017)

Water scarcity incidences and when such incidences occurred were recorded as a measure of household water security. About $98 \%$ of households rely on boreholes and dams as their main water source. Only $2 \%$ of households noted rain (harvesting) as a source of water for households. Households water sufficiency rating reveals that the majority of households (83\%) considered water "somewhat available." Only 4\% of households reported that water is "sufficiently available." About 13\% considered "scarcely available." No significant difference was noted between wards. Duration wise, the majority of households $(80 \%)$ reported experiencing water scarcity up to six of the previous twelve months. The months in which water scarcity incidents were experienced are presented in Fig. 7.

Several inferences can be made from these results. Firstly, most households have insufficient water available to meet year-round demand. Secondly, water scarcity coincides with the dry season indicating high seasonal household dependence on climate-sensitive water sources including rain-charged dams as well as groundwater. Thirdly, as many households rely on boreholes for their water requirements, financial constraints could affect their ability to access life-essential water.

In a study that examined the economic and environmental change in Niger, McKune and Silva (2013) linked erratic rainfall and increasing temperature to increasing threats to household water supply and the sustainability of their livelihoods overall. These authors also noted globalization as a driver of local vulnerability. Hence, in addition to the observed increase in the recorded measures of vulnerability, regional and global socio-economic stressors may have further locallevel resource dynamic and vulnerability implications. In Tanzania and particularly 


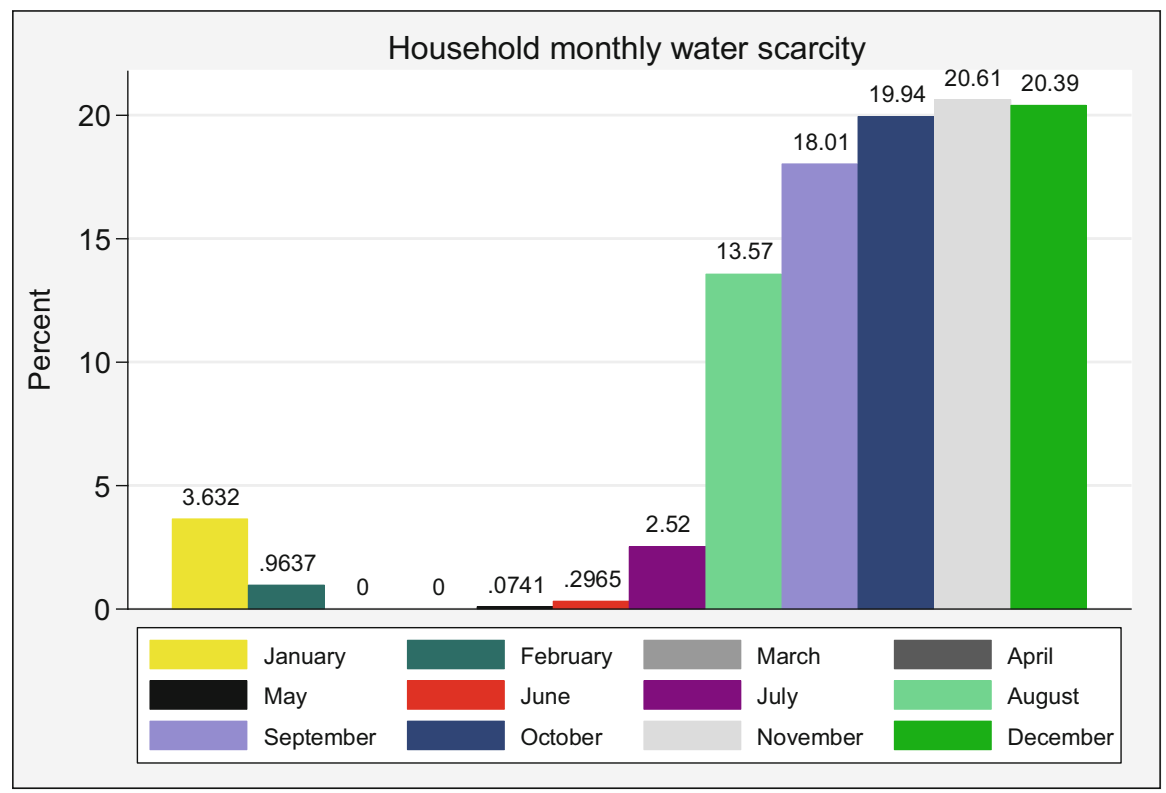

Fig. 7 Monthly household water scarcity incidents (numbers above the bars indicate percentage frequency). (Source: Ndesanjo 2017)

Simanjiro District, large scale foreign direct investments have been associated with pastoralists disenfranchisement potentially exacerbating their vulnerability to prevailing socio-ecological stresses and shocks (Hodgson 2011).

The prevalence of diseases was used as another measure of climate change impacts. About $69 \%$ of households reported malaria the most prevalent disease. Diarrhea, malnutrition, and "magical-related" illnesses such as curses were mentioned by only $2 \%$ of surveyed households. The majority of households $(82 \%)$ indicated that illness affected them for up to five months. Only a few households $(9 \%)$ reported illness affecting them up to six of the previous twelve months. Illness incidents were concentrated between February and July (Fig. 8).

Malaria prevalence is largely influenced by climatic conditions such as temperature and humidity which determine the procreation of its vectors which are mosquitoes (Irish Aid 2018). This likely explains the high frequency of malaria cases in the months of the wet season. The Maasai are known for their knowledge of herbs for traditional medicine (Kiringe 2006; Sindiga 1994). Hence, the high number of malaria cases despite this knowledge may imply an increasing trend of diseases that were previously uncommon in semi-arid areas like Simanjiro District and against which traditional ecological knowledge holds no remedies (van Lieshout et al. 2004).

Approximately, $63 \%$ of households use modern treatments as their main disease control mechanism, whereas about $34 \%$ opt for traditional treatment. However, both options were reportedly used interchangeably. The use of traditional treatments may, 


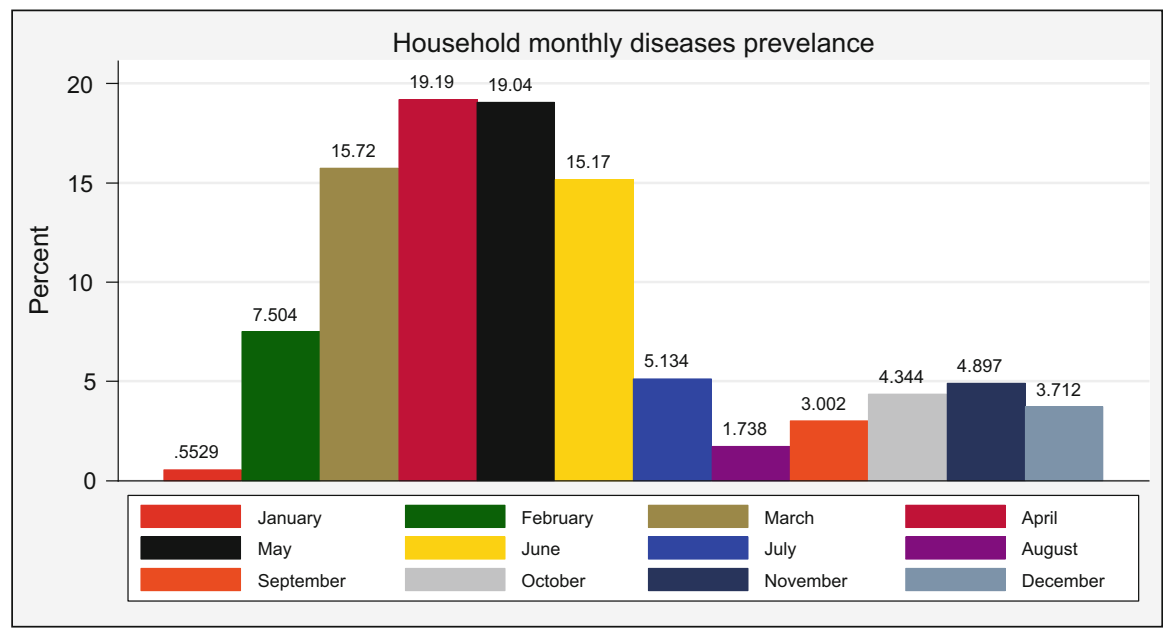

Fig. 8 Monthly household disease prevalence (numbers above the bars indicate percentage frequency). (Source: Ndesanjo 2017)

however, be under-reported here because mainly women seek this treatment including when children are ill and this may occur without the involvement of male household heads who were the respondents of this study. Modern treatments are likely to draw the attention of households' heads as this has financial implications that may require their consultation, whereas traditional medicine may be collected from the surrounding environment. Furthermore, traditional medicines are commonly used not only when a household member falls sick.

\section{Climate Change Adaptive Strategies}

This section addresses adaptive strategies employed by pastoralists in the study area in response to increasing climate variability and directional climate change. The majority of households $(98 \%)$ indicated that they had food security enhancement strategies in place in the previous twelve months. About $72 \%$ of the households indicated that food reserves were the food security strategy employed. Seed banking was another food security strategy reported used, albeit by fewer households (22\%). This implies that most households take the food security question seriously and prepare for shocks.

Households were also asked about alternative mechanisms employed when common food security mechanisms (food reserve and seed banks) failed following shocks such as livestock mortality and crop failure. About 58\% reported that they resort to selling livestock while the rest $(17 \%)$ mentioned liquefying household assets in response to shocks (Fig. 9).

These findings suggest that households' ability to purchase food is the most important food security strategy. A study by Miller et al. (2014) found that when 


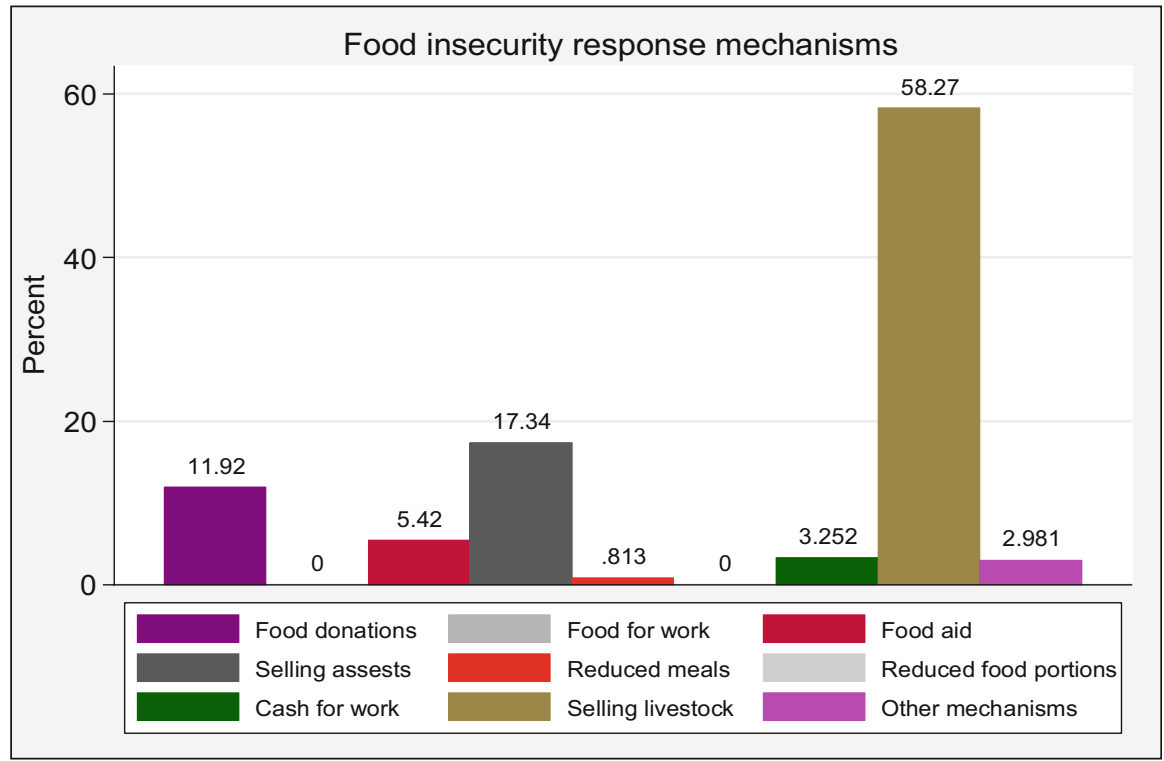

Fig. 9 Household food insecurity response mechanisms (numbers above the bars indicate percentage frequency). (Source: Ndesanjo 2017)

the situation is critical, pastoral households even purchase pasture access rights and other livestock feeds in addition to food for household members. Hence, the affordability of purchased food is critical for households to stay afloat during periods with severe food scarcity. This means that a reliable income source and asset base is crucial for household response to climate shocks as well as to directional climate change. Other studies have shown that the motivation for selling livestock in most pastoral households is to raise money with which to buy food (Pauline et al. 2017; Silvestri et al. 2012; Suckall et al. 2014).

Responses on strategies used to maintain water security indicate that about $60 \%$ of households have a water storage mechanism in place. Other strategies used to ensure water security are presented in Fig. 10. Households were further asked about the strategies used when they encounter acute water shortage especially when their regular strategies to secure water prove futile. About $42 \%$ reported that they substantially reduce their water usage. Others (40\%) reported that the most ideal option is migrating temporarily to areas where water is accessible.

The predominance of water storage may arise from the fact that the studied wards are not serviced by piped water thus leaving water-storing as the main option. This result resonates with findings by (Trærup and Mertz 2011) in Northern Tanzania who found the absence of piped water to be the main determinant of water storage mechanisms. More importantly, the prevalence of water storage as an adaptation strategy may arise from the semi-arid condition of Simanjiro District most of the year, otherwise forcing people to cover relatively long distances on foot in search of water (Smith et al. 2000).

As water scarcity intensifies, the most prudent response mechanism is to reduce water consumption (Miller et al. 2014). This means limiting water use to cooking 


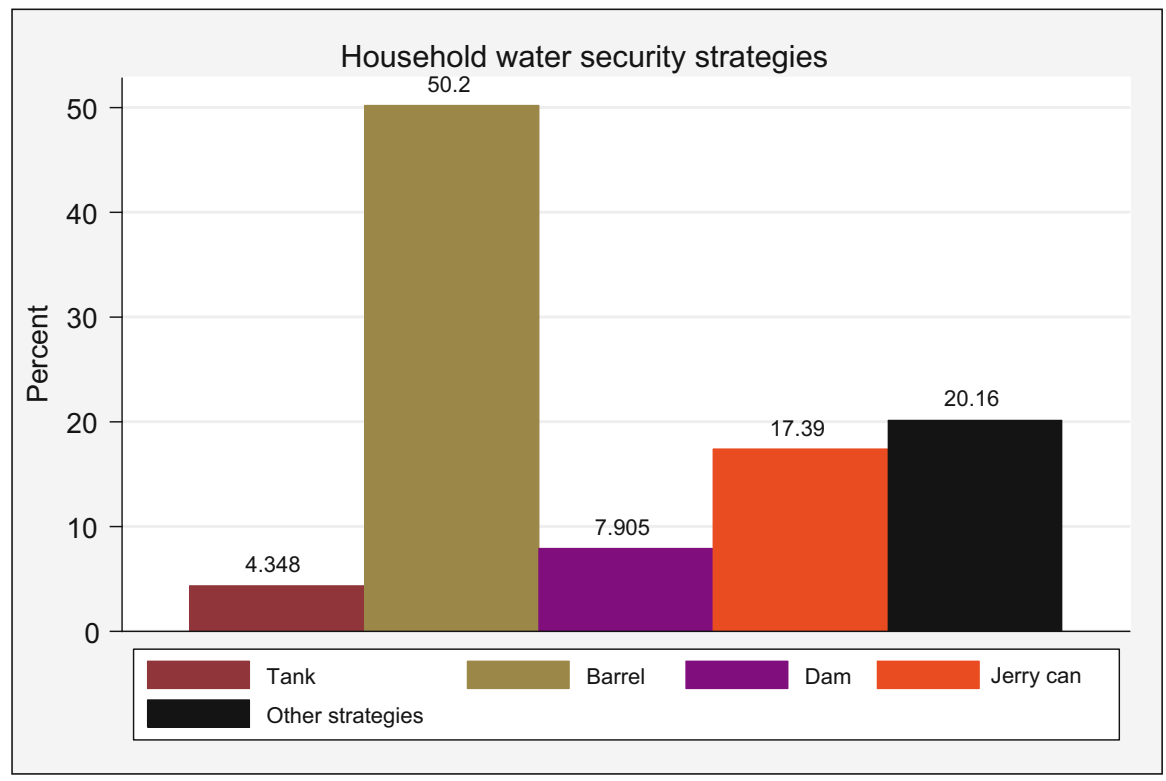

Fig. 10 Household water security strategies (numbers above the bars indicate percentage frequency). (Source: Ndesanjo 2017)

and minimal washing only. People often have to compete for water among themselves as well as with livestock for water during the dry season and the price of water from private boreholes often increases due to the high demand. Noticeably, water allocation in times of scarcity tends to favour livestock over people. Consequently, only those with sufficient financial resources will have access to water. As a result households are compelled to reduce their water use. These results deviate from those of Miller et al. (2014) who associated water scarcity in Simanjiro District with the replacement of customary arrangements with local government water resources management arrangements.

Water scarcity is a common determinant of migration among pastoral communities (Berkhout 2012; Brockhaus et al. 2013). However, only a small segment of household members temporarily migrates with herds to other areas in search of water. The migration of an entire household was very common before the Ujamaa socialism program in Tanzania in the 1970s (Hodgson 2004). Implementation of the program saw massive resettlement and sedentarization across Maasailand in Tanzania, which has substantially altered the migration patterns of pastoral communities in northern Tanzania.

\section{Local Institutional Mechanisms and Climate Change Resilience}

Information about the role of local institutional mechanisms in building climate change resilience was obtained from key informants $(n=24)$. One of the questions 
they were asked was to identify the nature of institutions that people approach for help in case of climatic shocks such as a drought. Based on responses, five categories of institutions were identified. All key informants interviewed $(n=24)$ indicated that that traditional leaders and the village government are the most common institutions approached for help. Local non-governmental organizations (NGOs) were another popular resort $(n=23)$. Civil society organizations (CSOs) $(n=10)$ and international NGOs $(n=2)$ were also mentioned as institutions that people approach for help.

The predominance of traditional leaders and the village government may be explained by the social organization of Massai societies and Tanzania's local government structure. Age is central for the social organization of Maasai society as duties and responsibilities are assigned according to age group (Ndagala 1991). Goldman and Riosmena (2013) describe that institutional frameworks among East African Maasai pastoralists are built on clan and age ties underpinned by decentralized leadership and traditional social networks. In the case of building resilience, local traditional leaders as the elders are in charge of resource control and allocation especially during periods of acute scarcity.

In Tanzania, the village council is the smallest local government unit overseeing day-to-day governance and development processes (Venugopal and Yilmaz 2010). This function makes the village government a must-go-to source for help whenever people encounter shocks that they are unable to handle. Similarly, interventions aimed at addressing local crises (including climate change) are channeled through village governments to people on the ground. Therefore, when people seek government support, the village government is the first place they would go. Thus, this institution is crucial in promoting local level resilience to climate and other socio-economic shocks.

Key informants identified several types of support provided by local institutions for building resilience (Fig. 11). Agricultural inputs form most of the support provided by traditional leadership $(n=24)$, village government $(n=24)$, and

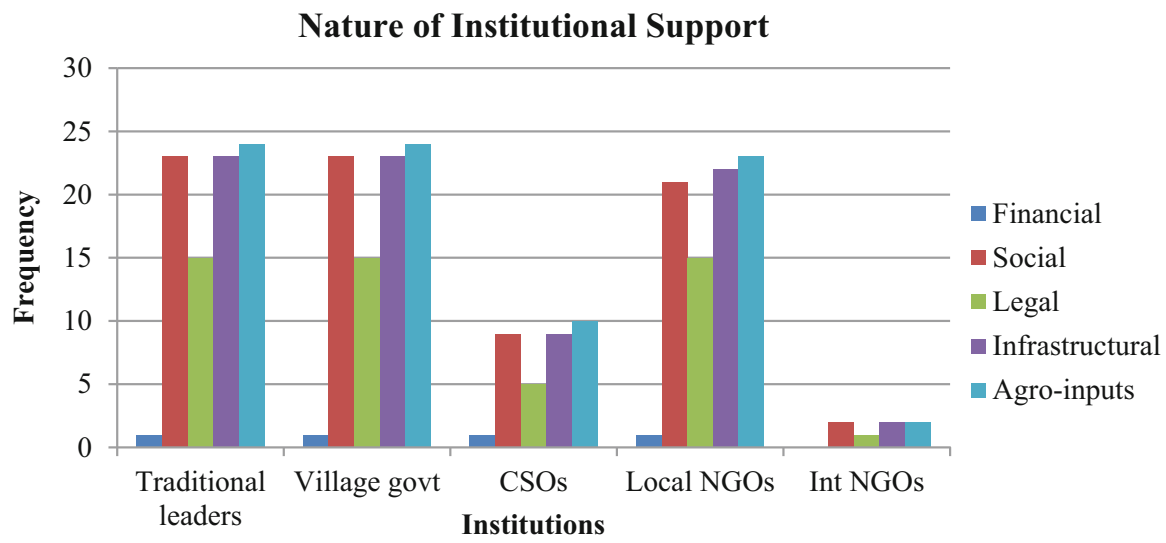

Fig. 11 Nature of support provided by local institutions. (Source: Ndesanjo 2017) 


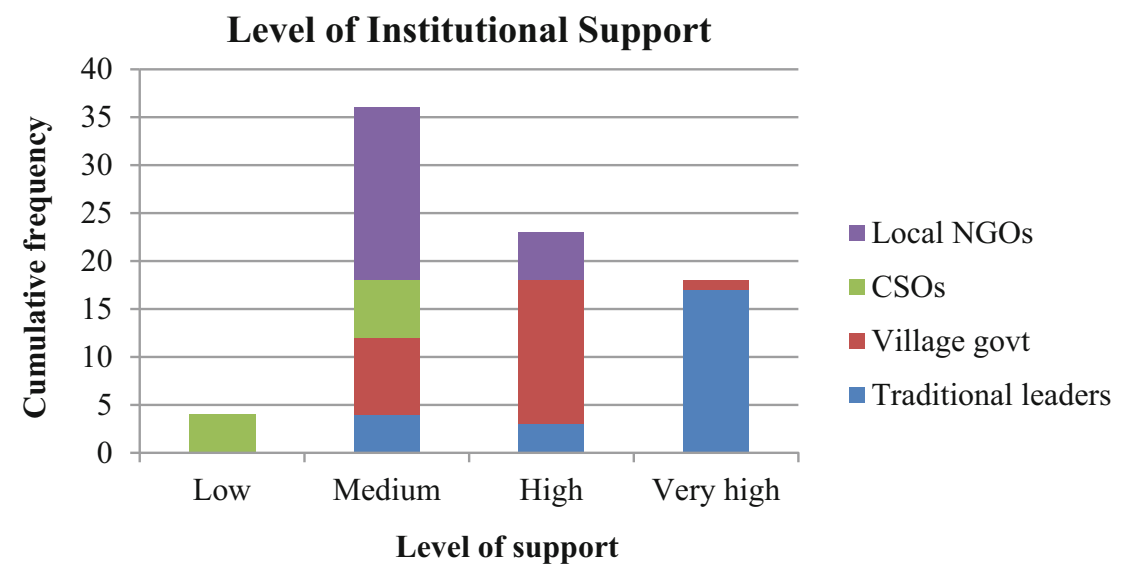

Fig. 12 Institutional support ranking. (Source: Ndesanjo 2017)

local nongovernmental organizations $(n=23)$. The same pattern was noted among civil society organizations $(n=10)$ and international nongovernmental organizations $(n=2)$. Other forms of support that were noted from the same institutions in order of their importance include infrastructural, social, legal, and financial support. Notably, unlike the rest of the institutions, financial support was not mentioned as provided by international nongovernmental organizations.

Institutional support in the form of agricultural inputs featured highest, possibly due to the dominant livelihood occupation, namely agro-pastoralism. This support was mainly in the form of extension services and disaster relief support when households succumb to shocks including mainly livestock mortality and crop failure due to drought. The role of local institutions in supporting local livelihoods and enhancing adaptability was noted in a study by Suckall et al. (2014) on community responses to climatic and socio-economic stresses in Zanzibar. The Zanzibar study found that local governments and cooperatives were instrumental in enhancing adaptive capacity not only through the provision of fishing and farming inputs but also providing market access assistance to local communities.

The level of support provided by institutions and their efficacy in promoting local resilience as ranked by key informants is presented in Fig. 12. Generally, most informants indicated that the level of support provided was medium. Traditional leaders were the highest-ranked local institution in terms of promoting local resilience followed by the village government. Local NGOs were ranked medium while civil society organizations were ranked lowest. Notably, international NGOs were not mentioned at all.

Traditional leaders affect the day-to-day life of pastoral communities particularly by leading people through extreme events such as drought. This explains the highly rated support of traditional leaders. The same applies to village governments. For example, findings by Miller et al. (2014) in Simanjiro-Tanzania indicate an increasing role of village committees in regulating resource use particularly water. 
However, these results differ from observation by Berkhout (2012) who show that local government institutions are considered unable to support local communities' climate adaptation strategies. Noteworthy, civil society organizations and local NGOs were not rated favorably which may be explained by claims that most such organizations among Maasai pastoral communities are founded on the pretext of supporting local communities but in reality, serve personal interests of the founders (Hodgson 2011; Igoe 2003).

\section{Limitations}

The study has limitations. It adopted a cross-sectional household survey approach and is thus subject to data reliability challenges in terms of the magnitude of income, crop harvests, livestock births and deaths, and climate impacts with the possibility of strategic answers. Nondisclosure tendency among respondents especially with livestock wealth was encountered in the study. This could have affected the validity of the information provided by respondents despite taking some remedial measures such as deploying Maa speakers as field enumerators as well as triangulating the information with local informants such as village leaders, extension officers, and elders. The study also relied on recalled information by respondents, which is not always accurate.

\section{Conclusions}

This study sought to understand pathways to enhance the resilience of pastoral households in Simanjiro District-Northern Tanzania to increasing climate variability and directional climate change. A forty-year climatic trend analysis revealed changes in both temperature and precipitation in the study area. Also, extreme climatic events particularly droughts have become more common from the 1990s onwards. Drought is the main climate-induced shock to increasing household vulnerability in terms of food insecurity and water scarcity. Increasing prevalence of malaria during the wet season may also be attributed to climate variability and directional change and constitutes an increasing health risk to pastoral households. The main adaptive strategies employed by households include livestock and asset selling to address food needs and water storing accompanied by reduced usage. Local institutions and primarily traditional leaders and village governments were reported as fundamental in building local climate resilience.

The study concludes as follows. First, following observed climate trends in the study area, surveyed households are likely experiencing and responding more to local variability of the climate than permanent long-term shifts in the climate system. Second, country and regional level climate trends obscure local (district and village) level climate situations. Third, seasonal deterministic trends of food and water availability and/or scarcity as well as disease prevalence indicate the direct influence of local climate on household livelihoods. Fourth, diversifying livelihoods 
from agro-pastoralism and migrating to areas better endowed with resources such as water are important pathways to climate resilience. Finally, due to social proximity and mutual understanding between local communities and their local (traditional) leaders, these (leaders) play a crucial role in promoting local level resilience building.

It is recommended that creating mechanisms to monitor the local climate and regularly inform local communities is crucial to enable them to adjust their activities accordingly. Such an exercise should reflect the local context in terms of information dissemination and uptake as well as local livelihoods and seasonality. Also, a gradual and medium to long-term livelihood diversification initiative is a highly recommended policy strategy to increase resilience among pastoral communities as opposed to the current policy which condemns pastoralism as a backward and environmentally destructive activity. Finally, future research on local climate resilience should focus on evaluating livelihood diversification scenarios and assess trajectories. Equally, local knowledge systems and institutions should buttress policy-making and implementation to promote local resilience.

Acknowledgments Funding for this research was provided by the Danish International Development Agency (DANIDA) through the Building Stronger Universities in Developing Countries (BSU) programme. The writing of this paper was supported by the Nordic Africa Institute (NAI), through the African Guest Researchers' Scholarship Programme.

\section{References}

Angelsen A, Larsen H, Olsen C (2012) Measuring livelihoods and environmental dependence: methods for research and fieldwork. Routledge, London. https://doi.org/10.4324/ 9781849775694

Baird T (2014) Conservation and unscripted development: proximity to park associated with development and financial diversity. Ecol Soc 19(1):art4. https://doi.org/10.5751/ES06184-190104

Baird T, Leslie P (2013) Conservation as disturbance: upheaval and livelihood diversification near Tarangire National Park, Northern Tanzania. Glob Environ Chang 23(5):1131-1141. https://doi. org/10.1016/j.gloenvcha.2013.05.002

Berkhout F (2012) Adaptation to climate change by organizations: adaptation to climate change by organizations. Wiley Interdiscip Rev Clim Chang 3(1):91-106. https://doi.org/10.1002/wcc.154

Brockhaus M, Djoudi H, Locatelli B (2013) Envisioning the future and learning from the past: adapting to a changing environment in northern Mali. Environ Sci Pol 25:94-106. https://doi. org/10.1016/j.envsci.2012.08.008

Chambers R, Conway G (1992) Sustainable rural livelihoods: practical concepts for the 21st century. IDS Discussion Paper 296. IDS, Brighton

Godber O, Wall R (2014) Livestock and food security: vulnerability to population growth and climate change. Glob Chang Biol 20(10):3092-3102. https://doi.org/10.1111/gcb.12589

Goldman M, Riosmena F (2013) Adaptive capacity in Tanzanian Maasailand: changing strategies to cope with drought in fragmented landscapes. Glob Environ Chang 23(3):588-597. https://doi. org/10.1016/j.gloenvcha.2013.02.010

Hodgson D (2004) Once intrepid warriors: gender, ethnicity, and the cultural politics of Maasai development. Indiana University Press, Bloomington 
Hodgson D (2011) Being Maasai, becoming indigenous: postcolonial politics in a neoliberal world. Indiana University Press, Bloomington

Homewood K (2004) Policy, environment and development in African rangelands. Environ Sci Pol 7(3):125-143. https://doi.org/10.1016/j.envsci.2003.12.006

Homewood K, Kristjanson P, Trench P (eds) (2009) Staying Maasai? Livelihoods, conservation, and development in East African rangelands. Springer, New York

Igoe J (2003) Scaling up civil society: donor money, NGOs and the pastoralist land rights movement in Tanzania. Dev Chang 34(5):863-885. https://doi.org/10.1111/j.14677660.2003.00332.x

Irish Aid (2018) Tanzania country climate change risk assessment report. Resilience and Economic Inclusion Team, Policy Unit, Dar es Salaam

Kangalawe R (2017) Climate change impacts on water resource management and community livelihoods in the southern highlands of Tanzania. Clim Dev 9(3):191-201

Kiringe J (2006) A survey of traditional health remedies used by the Maasai of Southern Kaijiado District, Kenya. Ethnobot Res Appl 4:061-074

Lynn S (2010) In: Fort Collins (ed) The pastoral to agro-pastoral transition in Tanzania: human adaptation in an ecosystem context. Graduate Degree Program in Ecology. Colorado State University. Retrieved from http://economics-of-cc-in-tanzania.org/images/Stacy_Lynn_Pastoral ism_TZ_Draft_2010_08-09_draft.pdf

McCabe J, Leslie P, DeLuca L (2010) Adopting cultivation to remain pastoralists: the diversification of Maasai livelihoods in Northern Tanzania. Hum Ecol 38(3):321-334. https://doi.org/ 10.1007/s10745-010-9312-8

McKune S, Silva J (2013) Pastoralists under pressure: double exposure to economic and environmental change in Niger. J Dev Stud 49(12):1711-1727. https://doi.org/10.1080/ 00220388.2013.822067

Mertz O, Mbow C, Reenberg A, Diouf A (2009) Farmers' perceptions of climate change and agricultural adaptation strategies in rural Sahel. Environ Manag 43(5):804-816. https://doi.org/ 10.1007/s00267-008-9197-0

Miller B, Leslie P, McCabe J (2014) Coping with natural hazards in a conservation context: resource-use decisions of Maasai households during recent and historical droughts. Hum Ecol 42(5):753-768. https://doi.org/10.1007/s10745-014-9683-3

Ndagala D (1991) Pastoralism and rural development: the Ilparakuyo experience. Reliance Publishing House, New Dehli

Ndesanjo R (2017) Pathways to enhance climate change resilience among pastoral households in Simanjiro District-Northern Tanzania. Unpublished PhD thesis, University of Dar es Salaam, Dar es Salaam

Orlove B (2019) Climate change and the quality of growth in Africa. In: Akbar N, Stiglitz JE, Kanbur R (eds) The quality of growth in Africa. Columbia University Press, New York, pp 325-349

Paavola J (2008) Livelihoods, vulnerability and adaptation to climate change in Morogoro, Tanzania. Environ Sci Pol 11(7):642-654. https://doi.org/10.1016/j.envsci.2008.06.002

Pardoe J, Conway D, Namaganda E, Vincent K, Dougill A, Kashaigili J (2018) Climate change and the water-energy-food nexus: insights from policy and practice in Tanzania. Clim Pol 18 (7):863-877. https://doi.org/10.1080/14693062.2017.1386082

Pauline N, Vogel C, Grab S, Liwenga E (2017) Smallholder farmers in the Great Ruaha River subBasin of Tanzania: coping or adapting to rainfall variability? Clim Dev 9(3):217-230. https:// doi.org/10.1080/17565529.2016.1184607

Pittiglio C, Skidmore A, van Gils H, Prins H (2012) Identifying transit corridors for elephant using a long time-series. Int J Appl Earth Obs Geoinf 14(1):61-72. https://doi.org/10.1016/j. jag.2011.08.006

Reed M, Podesta G, Fazey I, Geeson N, Hessel R, Hubacek K, Thomas A (2013) Combining analytical frameworks to assess livelihood vulnerability to climate change and analyse adaptation options. Ecol Econ 94:66-77. https://doi.org/10.1016/j.ecolecon.2013.07.007 
Rodima-Taylor D (2012) Social innovation and climate adaptation: local collective action in diversifying Tanzania. Appl Geogr 33:128-134. https://doi.org/10.1016/j.apgeog.2011.10.005

Sewando PT, Mutabazi KD, Mdoe NYS (2016) Vulnerability of agro-pastoral farmers to climate risks in northern and central Tanzania. Dev Stud Res 3(1):11-24

Silvestri S, Bryan E, Ringler C, Herrero M, Okoba B (2012) Climate change perception and adaptation of agro-pastoral communities in Kenya. Reg Environ Chang 12(4):791-802. https://doi.org/10.1007/s10113-012-0293-6

Sindiga I (1994) Indigenous (medical) knowledge of the Maasai. Indig Knowl Dev Monit 2 (1): $16-18$

Smith K, Barrett C, Box P (2000) Participatory risk mapping for targeting research and assistance: with an example from East African pastoralists. World Dev 28(11):1945-1959

Suckall N, Tompkins E, Stringer L (2014) Identifying trade-offs between adaptation, mitigation and development in community responses to climate and socio-economic stresses: evidence from Zanzibar, Tanzania. Appl Geogr 46:111-121. https://doi.org/10.1016/j.apgeog.2013.11.005

Suryabhagavan K (2017) GIS-based climate variability and drought characterization in Ethiopia over three decades. Weather Clim Extrem 15:11-23. https://doi.org/10.1016/j. wace.2016.11.005

Trærup S, Mertz O (2011) Rainfall variability and household coping strategies in Northern Tanzania: a motivation for district-level strategies. Reg Environ Chang 11(3):471-481. https:// doi.org/10.1007/s10113-010-0156-y

van Lieshout M, Kovats R, Livermore M, Martens P (2004) Climate change and malaria: analysis of the SRES climate and socio-economic scenarios. Glob Environ Chang 14(1):87-99. https:// doi.org/10.1016/j.gloenvcha.2003.10.009

Venugopal V, Yilmaz S (2010) Decentralization in Tanzania: an assessment of local government discretion and accountability. Public Adm Dev 30(3):215-231

Woodhouse E, McCabe J (2018) Well-being and conservation: diversity and change in visions of a good life among the Maasai of Northern Tanzania. Ecol Soc 23(1):43. https://doi.org/10.5751/ ES-09986-230143

Open Access This chapter is licensed under the terms of the Creative Commons Attribution 4.0 International License (http://creativecommons.org/licenses/by/4.0/), which permits use, sharing, adaptation, distribution and reproduction in any medium or format, as long as you give appropriate credit to the original author(s) and the source, provide a link to the Creative Commons license and indicate if changes were made.

The images or other third party material in this chapter are included in the chapter's Creative Commons license, unless indicated otherwise in a credit line to the material. If material is not included in the chapter's Creative Commons license and your intended use is not permitted by statutory regulation or exceeds the permitted use, you will need to obtain permission directly from the copyright holder.

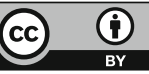

